\title{
Studies of metallacarborane derivatives containing aluminum and silicon
}

\author{
David M. Schubert, William S. Rees, Jr., Carolyn B. Knobler, \\ and M. Frederick Hawthorne* \\ Department of Chemistry and Biochemistry, The University of California, Los Angeles \\ 405 Hilgard Avenue, Los Angeles, CA 90024, USA
}

\begin{abstract}
Recent synthetic and structural studies of metallacarborane derivatives containing aluminum and silicon are described. These new compounds formally incorporate the nido-[7,8- $\left.\mathrm{C}_{2} \mathrm{~B}_{9} \mathrm{H}_{11}\right]^{2-}$ (dicarbollide), nido-[6,9- $\left.\mathrm{C}_{2} \mathrm{~B}_{8} \mathrm{H}_{10}\right]^{2-}$, and nido-[2,7- $\left.\mathrm{C}_{2} \mathrm{~B}_{6} \mathrm{H}_{8}\right]^{2-}$ carborane ligands. The reversible, thermal dimerization of $3-\mathrm{Et}-3,1,2-\mathrm{Al}$ $\mathrm{C}_{2} \mathrm{~B}_{9} \mathrm{H}_{11}$ (2) in solution to form commo-3,3'-Al[exo-8,9-( $\left.\mu-\mathrm{H}\right)_{2}-\mathrm{Al}$ $\left.\left.\left(\mathrm{C}_{2} \mathrm{H}_{5}\right)_{2}-3,1,2-\mathrm{AlC}_{2} \mathrm{~B}_{9} \mathrm{H}_{9}\right)\left(3^{\prime}, 1^{\prime}, 2^{\prime}-\mathrm{AlC}_{2} \mathrm{~B}_{9} \mathrm{H}_{11}\right)\right](3)$, which contains a novel commo- $\left[\mathrm{Al}\left(\eta^{5}-\mathrm{C}_{2} \mathrm{~B}_{9} \mathrm{H}_{11}\right)_{2}\right]^{-}$sandwich moiety is discussed. Reaction of $\mathrm{Na}\left[5,6-\mathrm{C}_{2} \mathrm{~B}_{8} \mathrm{H}_{11}\right]$ with $\mathrm{Et}_{2} \mathrm{AlCl} \cdot \mathrm{OEt}_{2}$ and $\mathrm{Et}_{2} \mathrm{AlCl}$ produces the symmetrically bridged nido-aluminacarboranes nido-6,9- $\mu$-AlEt $\left(\mathrm{OEt}_{2}\right)-6,9-$ $\mathrm{C}_{2} \mathrm{~B}_{8} \mathrm{H}_{10}$ (4) and $\mathrm{Na}\left[\mathrm{Al}\left(6,9-\mathrm{C}_{2} \mathrm{~B}_{8} \mathrm{H}_{10}\right)_{2}\right](\mathrm{Na}[5])$, respectively. Reaction of $\mathrm{Na}\left[1,3-\mathrm{C}_{2} \mathrm{~B}_{7} \mathrm{H}_{12}\right]$ with $\mathrm{Et}_{2} \mathrm{AlCl}$ gives $\mathrm{Na}\left[\mathrm{Al}\left(\eta^{2}-2,7-\mathrm{C}_{2} \mathrm{~B}_{6} \mathrm{H}_{8}\right)_{2}\right](\mathrm{Na}[6])$. Species 3, 4, and [6]- exhibit fluxional behavior in solution. Anicns $[5]^{-}$and $[6]^{-}$are unusual examples of bis( $\eta^{2}$-carboranyl)aluminate spiro-compounds. Finally, synthesis of the unusual bis $\left(\eta^{5}\right.$-carboranyl)silicon(IV) sandwich complex, commo-3,3'- $\mathrm{Si}-\left[3,1,2-\mathrm{SiC}_{2} \mathrm{~B}_{9} \mathrm{H}_{11}\right]_{2}(7)$, is described.
\end{abstract}

\section{INTRODUCTION}

Our ongoing studies of metallacarborane derivatives containing main group elements have recently lead to the synthesis and structural characterization of a number of new aluminum-containing metallacarboranes. The chemistry of these unusual species has turned out to be both surprising and diverse; and patterns of structure and reactivity for this class of compounds are beginning to emerge. Several unusual rearrangement reactions have been now elucidated and novel bonding modes which were previously unprecedented in the chemistry of aluminum have been observed. In addition, the concepts and methodologies developed through the study of aluminacarboranes have been extended to the chemistry of other elements with significant success, most notably in the recent synthesis of the first formal silicon(IV) sandwich compound (ref. 1) which is described herein.

A significant feature of the chemistry of aluminacarboranes appears to be the diversity of bonding modes which are possible between aluminum and various carborane cage moieties. Examples of stable, formally pentahapto- (ref. 2), trihapto- (ref. 3) and bis(pentahapto)- (ref. 4) aluminum-carborane $\pi$-bonding modes, as well as $\sigma$-bonded aluminum-to-carbon carborane cage interactions (refs. 5, 6), have now been documented. In addition, the occurrence of fluxional solution behavior for several of these species, which appears to be characteristic of these compounds, has been observed (refs. 2, 3, 5, 6, 7). The variety of potential bonding modes accessible to aluminum in aluminacarborane clusters, coupled with their high reactivity and fluxional lability, is descriptive of the chemistry of these unusual species. 
Aluminacarboranes are also of interest as reagents for the synthesis of other metallacarboranes since they are both soluble and possess suitably high reactivity. Viewed in this way, the aluminum atom can be regarded as a "sacrificial vertex" in transmetallation and other reactions leading to new cluster complexes which may be unobtainable by other methods. Thallacarboranes (ref. 8) have served as valuable synthetic reagents in recent years. The efficacy of using carborane reagents derived from main group elements in the synthesis of new metallacarboranes has been demonstrated by Hosmane with the use of a stannacarborane in the high yield synthesis of an unusual osmacarborane complex (ref. 9). More recently, Jutzi has exploited this methodology with the use of an aluminacarborane reagent in the preparation of several main group element-containing carborane derivatives (ref. 10). This potentially important use of aluminacarboranes and other main group element carborane derivatives remains largely unexplored.

Synthesis and characterization of icosahedral aluminacarboranes of the general type closo-3-R-3,1,2- $\mathrm{AlC}_{2} \mathrm{~B}_{9} \mathrm{H}_{11}(\mathrm{R}=\mathrm{Me}, 1 ; \mathrm{Et}, 2)$, as well as the gallacarborane analogue of 1 , closo-3-Me-3,1,2- $\mathrm{GaC}_{2} \mathrm{~B}_{9} \mathrm{H}_{11}$ have been described previously (ref. 2). The synthesis of these compounds is illustrated in Scheme 1. Initial reaction of nido-7,8- $\mathrm{C}_{2} \mathrm{~B}_{9} \mathrm{H}_{13}$ with the corresponding $\mathrm{ER}_{3}$ reagent $(\mathrm{E}=\mathrm{Al}, \mathrm{Ga} ; \mathrm{R}=$ alkyl $)$ in aromatic solvent results in the formation of relatively stable, isolable exo-nido metallacarboranes with concomitant loss of one equivalent of alkane. The structure of exo-nido- $\mu-9,10-\mathrm{AlMe}_{2}-\mu-(\mathrm{H})_{2}-7,8-\mathrm{C}_{2} \mathrm{~B}_{9} \mathrm{H}_{10}$, formed by reaction of nido- $\mathrm{C}_{2} \mathrm{~B}_{9} \mathrm{H}_{13}$ with $\mathrm{AlMe}_{3}$, has been determined by $\mathrm{X}$-ray diffraction (refs. 2a, b). Important structural features of these exo-nido species are the presence of a residual B-H-B bridging moiety and the connectivity of the dialkylaluminum moiety to the carborane cage via B-H-Al bridging groups. Upon heating, loss of a second equivalent of alkane occurs resulting in formation of the closo products. The structure of 2 has also been determined by X-ray diffraction (ref. 2b, c). While these closo metallacarboranes are air- and moisture-sensitive, they possess considerable thermal stability. Heating 2 at $400{ }^{\circ} \mathrm{C}$ in vacuo, conditions under which aluminum alkyls commonly undergo $\beta$-elimination, results only in polyhedral rearrangement of 2 to the corresponding 2,1,7-isomer, as shown in Scheme 1 . Compound 2 exhibits Lewis acid behavior, forming adducts with a variety of Lewis bases (refs. 2b, 3, 10). Synthesis of $2 \cdot(\mathrm{THF})_{2}$, from which THF could not be removed in vacuo, has been reported (ref. 11).

It has been discovered recently that 2 possesses catalytic reactivity for the polymerization of olefins and exchange of carborane $\mathrm{B}-\mathrm{H}$ and hydrocarbon $\mathrm{C}-\mathrm{H}$ hydrogen under mild conditions. The details of this chemistry will be described elsewhere (ref. 3).

\section{ALUMINACARBORANE MONOMER-DIMER EQUILIBRIA}

When benzene or toluene solutions of 2 are heated at $80{ }^{\circ} \mathrm{C}$ in a sealed NMR tube, a new aluminacarborane species can be detected which exists in equilibrium with 2 under these conditions. Solution molecular weight measurements of this new species (refs. 3, 4), which can be isolated in pure form by preferential sublimation of 2 , prove it to be a dimer of 2. The molecular structure of this species has now been determined by a single-crystal $X$-ray diffraction study, showing this species to be a novel bis $\left(\eta^{5}\right.$. dicarbollide)aluminum sandwich complex, commo-3,3'- $\mathrm{Al}\left[\right.$ exo-8,9- $(\mu-\mathrm{H})_{2}-\mathrm{Al}\left(\mathrm{C}_{2} \mathrm{H}_{5}\right)_{2}-3,1,2-$ $\left.\left.\mathrm{AlC}_{2} \mathrm{~B}_{9} \mathrm{H}_{9}\right)\left(3^{\prime}, 2^{\prime}, 1^{\prime}-\mathrm{AlC}_{2} \mathrm{~B}_{9} \mathrm{H}_{11}\right)\right](3)$. The structure of this complex, a formal dimer of 2 , is shown in Figure 1. This compound can also be formed by catalytic action of $\mathrm{CO}$ on 2 . 
Scheme 1

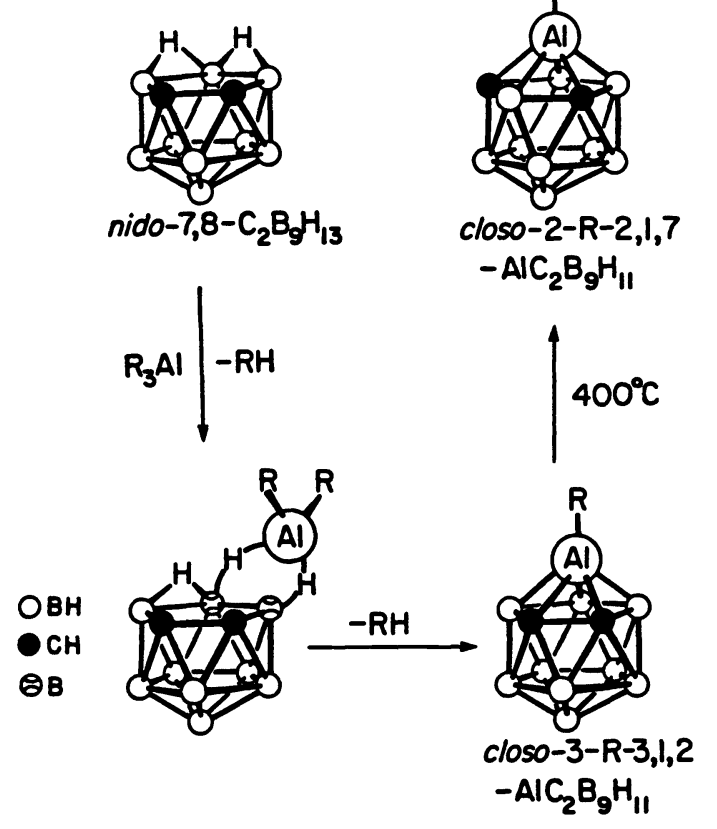

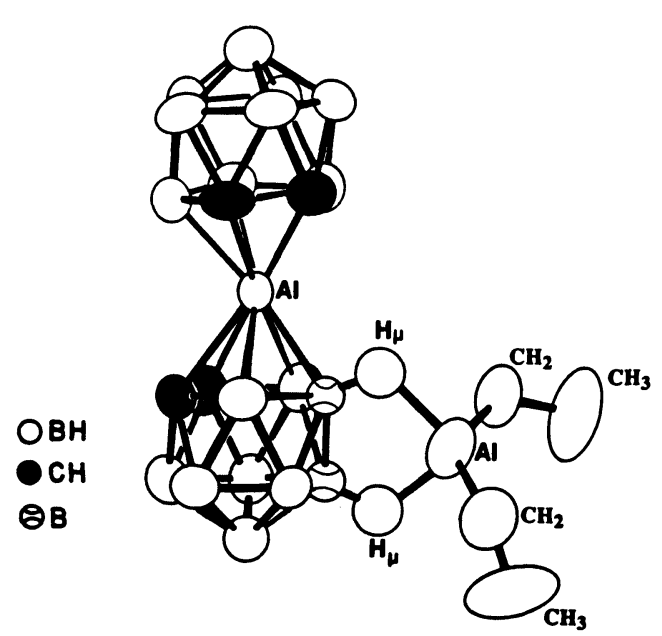

Figure 1. Structure of aluminacarborane dimer complex, 3, with all hydrogen atoms except those participating in bridging B-H-Al groups omitted for clarity.

Synthesis of aluminacarborane dicarbollide ligand derivatives.

The planar bonding faces of the two dicarbollide ligands in 3 are nearly parallel, making an angle of $2.6^{\circ}$ to one another, and are $\eta^{5}$-coordinated to the central aluminum atom in the same manner as ligands are bound in well-known transition metal sandwich complexes such as $\left[\mathrm{Fe}\left(\eta^{5}-\mathrm{C}_{5} \mathrm{H}_{5}\right)_{2}\right]$ (ref. 12) and $\left[\mathrm{Fe}\left(\eta^{5}-\mathrm{C}_{2} \mathrm{~B}_{9} \mathrm{H}_{11}\right)_{2}\right]^{\mathrm{n}-}(\mathrm{n}=1,2)$ (ref. 13). Additionally, a diethylaluminum moiety is bound to one of the dicarbollide cages via two B-H-Al bridges. Compound 3 may be regarded as a formal zwitterion composed of an anionic $\left[\mathrm{Al}\left(\eta^{5}-\mathrm{C}_{2} \mathrm{~B}_{9} \mathrm{H}_{11}\right)_{2}\right]^{-}$sandwich complexed with a $\left[\mathrm{Al}\left(\mathrm{C}_{2} \mathrm{H}_{5}\right)_{2}\right]^{+}$cation.

In addition to $\mathrm{X}$-ray crystal structure analysis, 3 has been characterized by a combination of ${ }^{1} \mathrm{H}$ and ${ }^{11} \mathrm{~B}$ NMR and IR spectroscopy. The presence of a single, relatively sharp, carboranyl $\mathrm{C}-\mathrm{H}$ resonance in the ${ }^{1} \mathrm{H}$ NMR spectrum as well as the apparent symmetry of the ${ }^{11 \mathrm{~B}}$ NMR spectrum is indicative of the occurrence of a fluxional process in solution. This process apparently involves cage rotation about the metal-carborane axis as well as a facile, intramolecular "cage walking" of the distal diethylaluminum moiety about the polyhedral carborane ligands. Intermolecular exchange of the distal diethylaluminum moiety is also possible and cannot be be ruled out on the basis of existing data. The dynamic behavior of 3 appears to persist even at $-80^{\circ} \mathrm{C}$ as indicated by a lack of any significant change in ${ }^{1} \mathrm{H}$ and ${ }^{11} \mathrm{~B}\left\{{ }^{1} \mathrm{H}\right\}$ NMR spectra acquired at this temperature.

Complex 3 represents an unusual example of a complex which contains a non-transition element in its highest oxidation state bonded between the parallel faces of two planar $\pi$ donor ligands. While sandwich compounds based on main group elements are known [e.g. $\mathrm{M}\left(\mathrm{C}_{5} \mathrm{Me}_{5}\right)_{2}, \mathrm{M}=\mathrm{Si}, \mathrm{Ge}, \mathrm{Sn}, \mathrm{Pb}$ (ref. 14)], these are 14 interstitial electron systems involving central atoms which possess a non-bonding electron pair. Complex 3 , on the other hand, contains a formal $\mathrm{Al}(\mathrm{III})$ atom. The central aluminum atom in 3 is bound nearly symmetrically with respect to the five atoms in each of the $\mathrm{C}_{2} \mathrm{~B}_{3}$ bonding faces of the two dicarbollide ligands. As each of these ligands is regarded as a 6-electron donor, the central aluminum atom formally has 12 electrons in its valence shell. There are no 
significant distortions in the structure of 3 which might be indicative of the presence of nonbonding electrons localized on the central atom. Thus, 3 represents a 12 interstitial electron system and the first commo-[Ne]-core main group element sandwich complex, as well as the only aluminum sandwich complex, of which we are aware.

\section{ALUMINACARBORANE nido-[6,9- $\left.\mathrm{C}_{2} \mathrm{~B}_{8} \mathrm{H}_{10}\right]^{2-}$ LIGAND DERIVATIVES}

The discovery of the novel reactivity for compound 2 mentioned above, has prompted attempts to prepare other aluminacarborane compounds derived from polyhedral carborane cages other than the dicarbollide cage. In an effort to prepare an elevenvertex analogue of 2 , reaction of diethylaluminum chloride-diethyl etherate with one equivalent of $\mathrm{Na}\left[5,6-\mathrm{C}_{2} \mathrm{~B}_{8} \mathrm{H}_{11}\right]$ (ref. 15) was carried out. This reaction takes place in refluxing toluene to give nido-[ $\left.\mu-6,9-\mathrm{AlEt}\left(\mathrm{OEt}_{2}\right)-6,9-\mathrm{C}_{2} \mathrm{~B}_{8} \mathrm{H}_{10}\right](4)$ as described by Equation 1 (ref. 5). Purification of the reaction product by high vacuum fractional distillation affords 4, a colorless, air- and water-sensitive liquid, in $77 \%$ yield. Fortuitously, crystals of a benzene solvate of $4\left(\mathrm{mp} 28-30{ }^{\circ} \mathrm{C}\right)$ can be obtained by careful recrystallization from benzene-pentane.

$$
\begin{aligned}
\mathrm{Na}\left[5,6-\mathrm{C}_{2} \mathrm{~B}_{8} \mathrm{H}_{11}\right]+\mathrm{Et}_{2} \mathrm{AlCl} \cdot \mathrm{OEt}_{2} \longrightarrow \text { nido-[ }\left[\mu-6,9-\mathrm{AlEt}\left(\mathrm{OEt}_{2}\right)-6,9-\mathrm{C}_{2} \mathrm{~B}_{8} \mathrm{H}_{10}\right] \\
+\mathrm{NaCl}+\mathrm{C}_{2} \mathrm{H}_{6}
\end{aligned}
$$

The structure of 4 has been determined by a single-crystal $X$-ray diffraction study of $4 \cdot 1 / 2\left(\mathrm{C}_{6} \mathrm{H}_{6}\right)$. This structure is shown in Figure 2. The polyhedral portion of 4 can be described as a nearly regular octadecahedron in which no one unique open face is present. The aluminum atom occupies a position on the pseudo-twofold axis of the cluster, being nearly equidistant from the four boron atoms as well as the two carbon atoms of the six-membered face of the carborane fragment, and thus can be regarded as occupying the eleventh octadecahedral vertex. The carboranyl carbon atoms occupy the 6- and 9-positions of the $\left[\mathrm{C}_{2} \mathrm{~B}_{8} \mathrm{H}_{10}\right]^{2-}$ ligand in agreement with observed spectroscopic data obtained for this species. The angles through the metal and between the two exopolyhedral substituents, and between the two carboranyl carbon atoms are roughly those anticipated for the accommodation of the tetrahedral bonding geometry of aluminum. The aluminum-boron interatomic distances average $2.51 \AA$, while the aluminum-carbon distances average $2.03 \AA$.

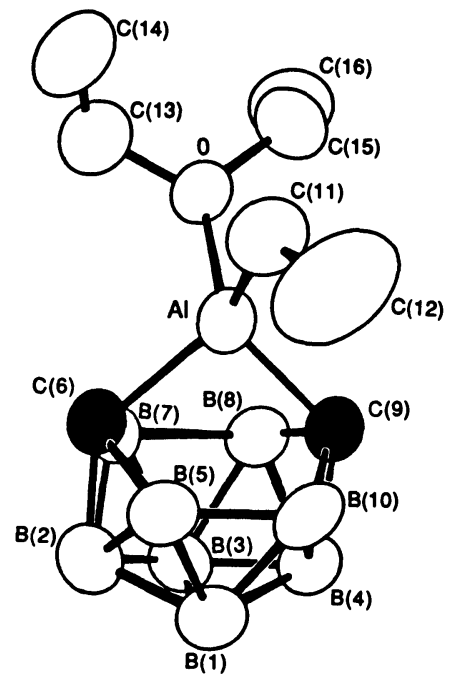

Figure 2.

Structure of nido-[6,9- $\left.\mu-\mathrm{AlEt}\left(\mathrm{OEt}_{2}\right)-6,9-\mathrm{C}_{2} \mathrm{~B}_{8} \mathrm{H}_{10}\right], 4$, with hydrogen atoms omitted for clarity. 
Rationalization of the observed geometry of 4 involves a description of the formally dianionic $\left[6,9-\mathrm{C}_{2} \mathrm{~B}_{8} \mathrm{H}_{10}\right]^{2-}$ cage as a nido $\eta^{2}$-ligand. This ligand can be viewed as donating four electrons via two carbon-based orbitals directed at two formal coordination sites of the tetrahedral aluminum cenler. The aluminum atom with its substituents can be regarded as a bridging, exopolyhedral moiety that does not participate in the polyhedral framework of the formally nido cluster.

The structure of 4 contrasts with that of other known main group element substituted, 11-vertex, 26-electron clusters [e.g. [ $\left.\mathrm{Me}_{2} \mathrm{M}\left(\eta^{4}-\mathrm{B}_{10} \mathrm{H}_{12}\right)\right](\mathrm{M}=\mathrm{Si}, \mathrm{Ge}, \mathrm{Sn})$ (ref. 16)] which adopt nido structures having a unique open face in which bridging B-H-B hydrogen atoms reside. Related transition metal complexes of the type nido-[ $\left.\mu-6,9-\mathrm{ML}_{2}-6,9-\mathrm{C}_{2} \mathrm{~B}_{8} \mathrm{H}_{10}\right](\mathrm{M}=$ $\mathrm{Pt}, \mathrm{L}=\mathrm{PPh}_{3}, \mathrm{SEt}_{2} ; \mathrm{M}=\mathrm{Ni}, \mathrm{L}=$ cis-1,2-( $\left.\left(\mathrm{NH}_{2}\right)_{2} \mathrm{C}_{6} \mathrm{H}_{4}\right)$, which bear structural similarity to 4 , have been reported recently (ref. 17). These involve square-planar rather than tetrahedral metal centers.

The ${ }^{11} \mathrm{~B}\left\{{ }^{1} \mathrm{H}\right\}$ NMR spectrum of 4 exhibits three resonances in a 1:2:1 area ratio indicative of $\mathrm{C}_{2 v}$ symmetry. This apparent symmetry can be attributed to rapid exchange of diethyl ether in solution. Upon addition of one equivalent of diethyl ether to a toluene- $d_{8}$ solution of 4 , only one set of diethyl ether ethyl resonances are observed in the ${ }^{1} \mathrm{H}$ NMR spectrum at room temperature. These resonances occur at chemical shifts intermediate between free and coordinated diethyl ether, indicating the occurrence of a rapid exchange process. VT NMR studies carried out down to $-90{ }^{\circ} \mathrm{C}$ fail to reveal any significant change in either the ${ }^{1} \mathrm{H}$ or the ${ }^{11} \mathrm{~B}\left\{{ }^{1} \mathrm{H}\right\}$ NMR spectra of 4 in toluene solution. Futhermore, low temperature ${ }^{1} \mathrm{H}$ NMR spectra of samples of 4 in toluene- $d_{8}$ containing added diethyl ether do not show two sets of ethyl resonances, but only one broad set of resonances. Low temperature ${ }^{11} \mathrm{~B}\left\{{ }^{1} \mathrm{H}\right\}$ NMR spectrum of these samples also fail to reveal any apparent loss of symmetry of the complex. The kinetic lability of coordinated diethyl ether in 4 can be further demonstrated by facile exchange with tetrahydrofuran (THF) resulting in the THF adduct nido-[ $\left.\mu-6,9-\mathrm{AlEt}\left(\mathrm{C}_{4} \mathrm{H}_{8} \mathrm{O}\right)-6,9-\mathrm{C}_{2} \mathrm{~B}_{8} \mathrm{H}_{10}\right]$. This species can be prepared independently by reaction of $\mathrm{Na}\left[5,6-\mathrm{C}_{2} \mathrm{~B}_{8} \mathrm{H}_{11}\right]$ with $\mathrm{Et}_{2} \mathrm{AlCl} \cdot \mathrm{THF}$. The high lability of coordinated ether in 4 may result from transient bonding interactions in solution of aluminum with boron atoms associated with the face of $\left[6,9-\mathrm{C}_{2} \mathrm{~B}_{8} \mathrm{H}_{10}\right]^{2-}$ ligand.

The mechanism of formation of 4 is unknown but may involve initial formation of an intermediate with the composition $\left[\mathrm{C}_{2} \mathrm{~B}_{8} \mathrm{H}_{11} \mathrm{AlEt}_{2}\left(\mathrm{OEt}_{2}\right)\right]$ having a residual $\mathrm{B}-\mathrm{H}-\mathrm{B}$ group. Elimination of ethane from this species would then lead to 4 or a species isomeric with 4 which differs in the relative positions of the carboranyl carbon atoms. Thermal rearrangement of the $\left[\mathrm{C}_{2} \mathrm{~B}_{8} \mathrm{H}_{10}\right]^{2-}$ ligand to produce the observed 6,9-isomer is expected for this system under the reaction condition as established by previous studies (ref. 18) and is consistent with the general pattern for thermal rearrangements of polyhedral carboranes for which carbon atoms tend to migrate to sites which are both separated from another and of low connectivity (ref. 19). This rearrangement also appears to provide the most suitable arrangement of ligand orbitals for bonding to the tetrahedral aluminum center.

Reaction of diethylaluminum chloride with two molar equivalents of $\mathrm{Na}\left[5,6-\mathrm{C}_{2} \mathrm{~B}_{8} \mathrm{H}_{11}\right]$ in refluxing toluene results in formation of $\mathrm{Na}\left[\mathrm{Al}\left(\eta^{2}-6,9-\mathrm{C}_{2} \mathrm{~B}_{8} \mathrm{H}_{10}\right)_{2}\right](\mathrm{Na}[5])$ as described by Equation 2 (ref. 6 ). The product, $\mathrm{Na}[5]$, a pale yellow, microcrystalline salt ( $\mathrm{mp}>300{ }^{\circ} \mathrm{C}$ ), 
is isolated in $81 \%$ yield. While $\mathrm{Na}[5]$ is moderately stable to dry air, it is hydrolyzed slowly when dissolved in water and, being hygroscopic, decomposes slowly in moist air. Cation exchange with [PPN]Cl resulted in conversion to PPN[5], an air stable, white crystalline solid $\left(\mathrm{mp}>300^{\circ} \mathrm{C}\right)$.

The ${ }^{11} \mathrm{~B}$ NMR spectra of $\mathrm{Na}[5]$ and PPN[5] each exhibit three doublet resonances in a 2:1:1 area ratio, consistent with a complex having $\mathrm{S}_{4}$ symmetry. The ${ }^{1} \mathrm{H}$ NMR spectra of $\mathrm{Na}$ [5] and PPN[5] in toluene- $d_{8}$ solution each display a single carboranyl C-H resonance. The IR spectra of these salts show bands characteristic of an anionic carborane complex ( $v 2543$ $\mathrm{cm}^{-1}, \mathrm{~B}-\mathrm{H}$ str.). The structure of the bis(carboranyl)aluminate anion [5]-, obtained by a single-crystal X-ray diffraction study of $\mathrm{PPN}[5]$ is shown in Figure 3 . The overall geometry of $\left[^{-5}\right]^{-}$is that of two octadecahedral clusters which share their unique vertex positions. The aluminum atom occupies this unique position common to both cages and is surrounded by a roughly tetrahedral array of four carbon atoms, each of which in turn occupies an apical position in one of two $6,9-\mathrm{C}_{2} \mathrm{~B}_{8} \mathrm{H}_{10}$ carborane moieties. The four aluminum-carbon interatomic distances average $2.06 \AA$ while the eight aluminum-boron distances average $2.53 \AA$. Bonding in [5]- can be rationalized in a manner similar to that used for complex 4 . The geometry and interatomic distances suggest that the aluminum atom participates in four sigma bonds with the nearby tetrahedrally disposed carbon atoms. The relatively long Al-B distances indicate an absence of direct bonding between aluminum and the nearby boron atoms. In this bonding picture, each of the $6,9-\mathrm{C}_{2} \mathrm{~B}_{8} \mathrm{H}_{10}$ cluster fragments are formally regarded as dianionic nido carborane cages which each donate four electrons via two carbon-based orbitals to $\mathrm{sp}^{3}$ hybrid orbitals of the formal Al(III) metal center having suitable symmetry. This bonding description allows the $[5]^{-}$ anion to be regarded as a spiro-aluminate complex.

The mechanism by which $[5]^{-}$is formed is not known, but undoubtedly involves successive loss of $\mathrm{NaCl}$ and elimination of two moles of ethane. Migration of the carbon atoms to the 6- and 9-positions of each nido- $\mathrm{C}_{2} \mathrm{~B}_{8} \mathrm{H}_{10}$ cage is, as with compound 4 , the expected thermal rearrangement for this system.

\section{SYNTHESIS OF AN ALUMINACARBORANE $\left[2,7-\mathrm{C}_{2} \mathrm{~B}_{6} \mathrm{H}_{8}\right]^{2-}$ LIGAND DERIVATIVE}

The synthesis of transition metal complexes possessing one or more of the isomeric dicarbazapide ligands $\left(\left[\mathrm{C}_{2} \mathrm{~B}_{7} \mathrm{H}_{9}\right]^{2-}\right)$ have been reported previously (ref. 20). These complexes are generally derived from $1,3-\mathrm{C}_{2} \mathrm{~B}_{7} \mathrm{H}_{13}$ (ref. 21) or its salts, $\mathrm{Na}\left[1,3-\mathrm{C}_{2} \mathrm{~B}_{7} \mathrm{H}_{12}\right]$ and $\mathrm{Na}_{2}\left[1,3-\mathrm{C}_{2} \mathrm{~B}_{7} \mathrm{H}_{11}\right]$. Recently, in an attempt to obtain an aluminum-dicarbazapide ligand derivative, the reaction of the diethyl ether solvate of $\mathrm{Na}\left[1,3-\mathrm{C}_{2} \mathrm{~B}_{7} \mathrm{H}_{12}\right]$ with diethylaluminum chloride was examined. The reaction of these species in refluxing toluene in a 2:1 mole ratio, respectively, results in the unexpected formation of the unusual bis(carboranyl)aluminate complex, $\mathrm{Na}\left[\mathrm{Al}\left(\eta^{2}-2,7-\mathrm{C}_{2} \mathrm{~B}_{6} \mathrm{H}_{8}\right)_{2}\right](\mathrm{Na}[6])$ (ref. 7). This salt, an air-sensitive, white, crystalline solid, was isolated in $42 \%$ yield.

Since the structure of $\mathrm{Na}[6]$ could not be determined on the basis of spectroscopic data alone, a single crystal X-ray study of this compound was undertaken. This study revealed two crystallographically independent forms of $[6]^{-}$which were found to be enantiomeric stereoisomers, each associated with a sodium cation. The structure of one enantiomer of $\mathrm{Na}[6]$ is shown in Figure 4. Since the two enantiomeric form of $[6]^{-}$are 


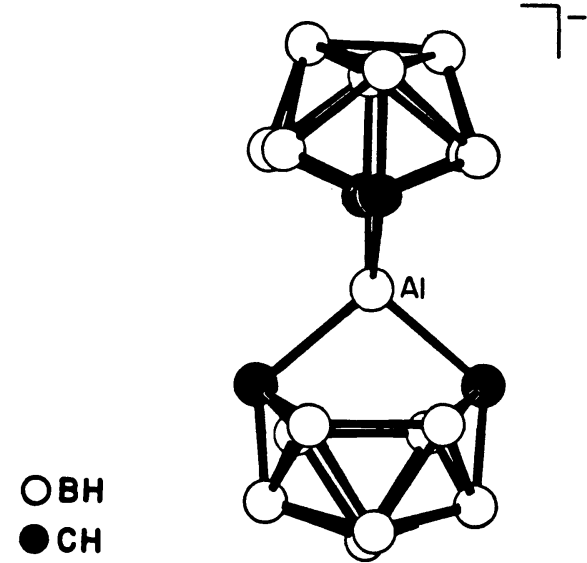

Figure 3. Structure of the anion $\left[\mathrm{Al}\left(\eta^{2}-6,9-\mathrm{C}_{2} \mathrm{~B}_{8} \mathrm{H}_{10}\right)_{2}\right]^{-},[5]^{-}$, with hydrogen atoms omitted for clarity.

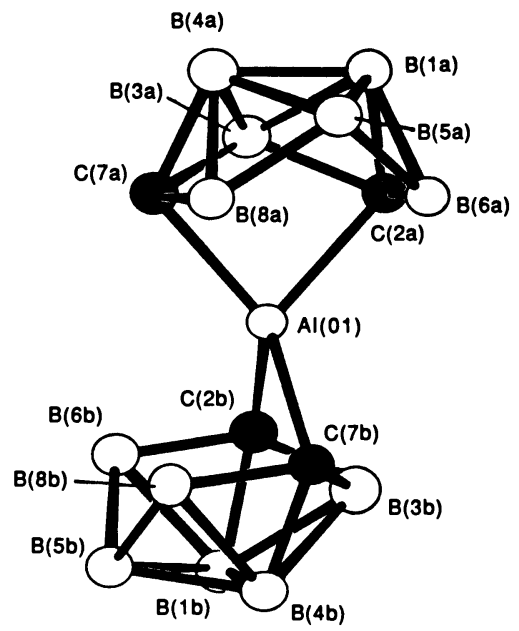

Figure 4. Structure of one enantiomer of $\mathrm{Na}\left[\mathrm{Al}\left(\eta^{2}-2,7-\mathrm{C}_{2} \mathrm{~B}_{6} \mathrm{H}_{8}\right)_{2}\right], \mathrm{Na}[6]$, with hydrogen atoms omitted for clarity.

chemically identical with the exception of chirality they will be discussed here as one complex. The aluminum center in [6] $]^{-}$is surrounded by a distorted tetrahedral array of four carboranyl carbon atoms, the two metal-ligand C-Al-C angles being nearly equal and averaging $82.14^{\circ}$. The four Al-C bond lengths are also nearly equal and average $2.020 \AA$. The shortest Al-B interatomic distances are those to the boron atoms in the ligand 3 positions which average $2.280 \AA$. The interatomic distances between the aluminum center and the four boron atoms which occupy the 6 and 8 ligand positions are longer still, averaging $2.508 \AA$.

Bonding in $[6]^{-}$is ostensibly similar to that in $[5]^{-}$as the formal nido- $\left[2,7-\mathrm{C}_{2} \mathrm{~B}_{6} \mathrm{H}_{8}\right]^{2-}$ ligand can be viewed as donating four electrons to the aluminum center via two filled carbon-based orbitals directed roughly at tetrahedral coordination sites on the metal. The relatively long aluminum-boron interatomic distances, as well as the coordination geometry around aluminum, suggests the absence of significant aluminum-boron bonding in this complex. Complex [6] $]^{-}$, like $[5]^{-}$, can be thought of as a spiro-aluminate complex.

Complex [6]- appears to display dynamic solution behavior as indicated by NMR studies. Due to its asymmetry, this complex would be expected to give rise to six lines in the ${ }^{11} \mathrm{~B}\left\{{ }^{1} \mathrm{H}\right\}$ NMR spectrum. Room temperature ${ }^{11} \mathrm{~B}\left\{{ }^{1} \mathrm{H}\right\}$ NMR spectra of toluene solutions of $\mathrm{Na}[6]$, however, exhibit only four relatively broad resonances at 22.1 (area 2), 7.6 (area 1), -13.8 ( area 1), and $-32.0 \mathrm{ppm}$ (area 2). The two area 2 resonances were assigned to the two pairs of boron atoms which lie off the local mirror plane of the $2,7-\mathrm{C}_{2} \mathrm{~B}_{6} \mathrm{H}_{8}$ cage. These resonances are broad and do not show clean proton splitting without ${ }^{1} \mathrm{H}$ decoupling. Upon warming the solution to $70^{\circ} \mathrm{C}$ the four resonances sharpen and the three highest field resonances exhibit clear ${ }^{1} \mathrm{H}$ coupling. The fourth low field area 2 resonance, however, remains broad. Upon cooling, the ${ }^{11} \mathrm{~B}$ NMR resonances become extremely broad and then sharpen again below $-80{ }^{\circ} \mathrm{C}$. At $-90^{\circ} \mathrm{C}$, the ${ }^{11} \mathrm{~B}\left\{{ }^{1} \mathrm{H}\right\} \mathrm{NMR}$ spectrum exhibits five resonances, the highest field area 2 resonance being replaced by two area 1 resonances at -26.9 and $-28.8 \mathrm{ppm}$. The low field area 2 resonance remains broad at all temperatures. The room temperature ${ }^{1} \mathrm{H}$ NMR spectrum of $\mathrm{Na}[6]$ in toluene$d_{8}$ solution exhibits a single carboranyl C-H resonance at $2.96 \mathrm{ppm}$ which sharpens 
somewhat upon warming to $70{ }^{\circ} \mathrm{C}$. Upon cooling, this resonance becomes broad and moves to somewhat higher field. Below $-80^{\circ} \mathrm{C}$ this resonance sharpens and is replaced at $-90{ }^{\circ} \mathrm{C}$ by two resonances at 2.63 and $2.92 \mathrm{ppm}$.

The observation of four resonances in the room temperature spectrum in a 2:1:1:2 area ratio suggests the occurrence of a fluxional process involving the interconversion of the two enantiomeric $[6]^{-}$anions. At $-90^{\circ} \mathrm{C}$ this interconversion is apparently slow enough on the NMR time scale to result in the appearance of two resonances for one of the boron position pairs which lie off the local mirror plane of the ligand. The broadness of the resonances attributable to the other off-plane boron atom pair may obscure the expected separation of these resonances. The variable temperature behavior of the ${ }^{1} \mathrm{H}$ NMR spectrum of the carboranyl $\mathrm{C}-\mathrm{H}$ protons, which lie off the local mirror plane of the ligand, corroborates this interpretation. The interconversion of the two [6]- enantiomers may occur via rotation of the nido- $\left[2,7-\mathrm{C}_{2} \mathrm{~B}_{6} \mathrm{H}_{8}\right]^{2-}$ ligands about the aluminum-carborane ligand axis. While direct aluminum-boron bonds do not appear to be present in the static structure of $[6]^{-}$, such bonding in the transition state of this dynamic process, particularly involving the boron atoms in the 3 positions, may occur and would avoid the necessity of a relatively high energy intermediate involving a square-planar aluminum center.

The loss of a boron vertex from the $\mathrm{C}_{2} \mathrm{~B}_{7}$ polyhedral cage is not unprecedented. The reaction of $\mathrm{Na}_{2}\left[1-\mathrm{R}-3-\mathrm{R}-1,3-\mathrm{C}_{2} \mathrm{~B}_{7} \mathrm{H}_{9}\right] \quad(\mathrm{R}=\mathrm{H}, \mathrm{Me})$ with $\mathrm{Mn}(\mathrm{CO})_{5} \mathrm{Br}$ or $\mathrm{Mn}_{2}(\mathrm{CO})_{10}$ to yield closo- $\left[\mathrm{C}_{2} \mathrm{~B}_{6} \mathrm{H}_{6} \mathrm{R}_{2} \mathrm{Mn}(\mathrm{CO})_{3}\right]^{-}(\mathrm{R}=\mathrm{H}, \mathrm{Me})$ has been reported previously (ref. 22). The mechanism whereby this $\mathrm{BH}$ vertex is lost is unknown. In the present case, a formal loss of $\mathrm{BH}_{3}$ and a proton from the [1,3- $\left.\mathrm{C}_{2} \mathrm{~B}_{7} \mathrm{H}_{12}\right]^{-}$anion is required for formation of the $[2,7-$ $\left.\mathrm{C}_{2} \mathrm{~B}_{6} \mathrm{H}_{8}\right]^{2-}$ ligand. However, examination of crude reaction mixtures by, ${ }^{1} \mathrm{H}$ and ${ }^{11} \mathrm{~B} \mathrm{NMR}$ spectroscopy reveals the presence of a complex mixture of boron-containing by-products, making a simple reaction mechanism for $[6]^{-}$formation difficult to support.

\section{SYNTHESIS OF A BIS( $\eta^{5}$-DICARBOLLIDE)SILICON SANDWICH COMPLEX}

The existence of commo sandwich complex 3 was immediately suggestive of the possibility of preparing an isoelectronic series of commo-[Ne]-core bis $\left(\eta^{5}\right.$-dicarbollide) main group element sandwich complexes of the type $\left[M\left(\eta^{5}-C_{2} B_{9} H_{11}\right)_{2}\right]^{n}$, where $M=A l(I I I), n=$ $1-; M=S i(I V), n=0 ; M=P(V), n=1+$. While complex 3 effectively represents the first member in this series, each of the other members of this series would be very interesting and would exhibit highly unusual bonding modes for these main group elements.

Reaction of silicon tetrachloride with two equivalents of $\mathrm{Li}_{2}$ [nido-7,8- $\left.\mathrm{C}_{2} \mathrm{~B}_{9} \mathrm{H}_{11}\right]$ in refluxing benzene results in the formation of commo-3,3'-Si(3,1,2-SiC $\left.{ }_{2} \mathrm{~B}_{9} \mathrm{H}_{11}\right)_{2}(7)$, according to Equation 3 (ref. 1). Compound 7 can be purified by sublimation in vacuo and isolated in

$2 \mathrm{Li}_{2}\left[\right.$ nido-7,8- $\left.\mathrm{C}_{2} \mathrm{~B}_{9} \mathrm{H}_{11}\right]+\mathrm{SiCl}_{4} \longrightarrow$ commo-3,3'-Si(3,1,2-SiC$\left.{ }_{2} \mathrm{~B}_{9} \mathrm{H}_{11}\right)_{2}+4 \mathrm{LiCl}$

78\% yield. This species is stable to dry air and soluble in most organic solvents, but is slowly decomposed by water. Compound 7 has been characterized by a combination of ${ }^{1} \mathrm{H},{ }^{11} \mathrm{~B}$, and ${ }^{13} \mathrm{C} \mathrm{NMR}$, IR, and mass spectroscopy, as well as by a single-crystal X-ray diffraction study. The 11B NMR spectrum of 7 exhibits resonances attributable to a single type of dicarbollide ligand. The ${ }^{1} \mathrm{H}$ NMR spectrum shows the presence of a single 


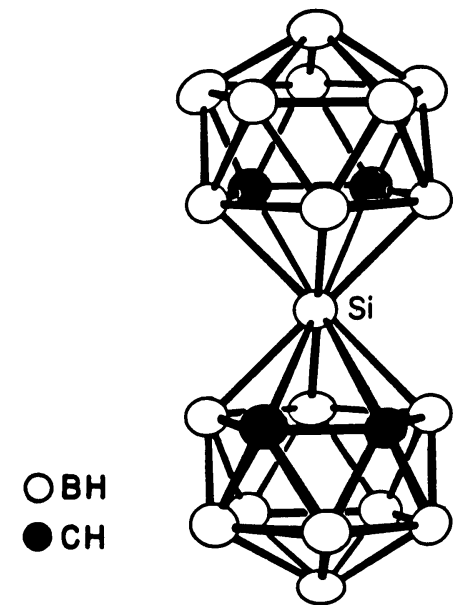

Figure 5.

Structure of commo-3,3'-Si(3,1,2-SiC $\left.\mathrm{B}_{2} \mathrm{H}_{11}\right)_{2}, 7$, with hydrogen atoms omitted for clarity.

Interatomic distances $(\AA)$ :

$\mathrm{Si}-\mathrm{C}(1,2)=2.22 \AA, \mathrm{Si}-\mathrm{B}(4,7)=2.14 \AA, \mathrm{Si}-\mathrm{B}(8)=2.05 \AA$.

carboranyl $\mathrm{C}-\mathrm{H}$ resonance in addition to broad $\mathrm{B}-\mathrm{H}$ resonances characteristic of the $[7,8$ $\left.\mathrm{C}_{2} \mathrm{~B}_{9} \mathrm{H}_{11}\right]^{2-}$ ligand. The IR spectrum contains a single carboranyl $\mathrm{C}-\mathrm{H}$ stretching band, in addition to the absorbances typically observed for the dicarbollide cage. The structure of 7, together with some selected interatomic distances, is shown in Figure 5. The silicon atom in 7 resides at a center of centrosymmetric crystallographic symmetry in the molecule, being equidistant between each of the two planar $C_{2} B_{3}$ dicarbollide bonding faces. Like 3, compound 7 represents a rare example of a sandwich compound which contains a main group element in its highest formal oxidation state bound between the faces of two planar $\pi$-donor ligands. Species 7 is sufficiently stable to undergo some conventional carborane cage derivatization reactions. The reactivity of 7 will be discussed elsewhere (ref. 23).

Hosmane has recently prepared and characterized an interesting series of new carborane derivatives of the general type $\left[\left(\mathrm{Me}_{3} \mathrm{Si}_{2}\right)_{2} \mathrm{C}_{2} \mathrm{~B}_{4} \mathrm{H}_{4}\right]_{2} \mathrm{M}$, where $\mathrm{M}$ is a group 14 element (ref. 24), which are closely related to 7 . The commo-silicon member of this series has been characterized by $\mathrm{X}$-ray diffraction and is structurally very similar to 7 .

Studies of carborane derivatives containing main group elements are continuing in our laboratory. In addition to providing metallacarboranes which possess unusual reactivity and exhibit novel bonding modes of purely theoretical interest, these compounds may be valuable as reagents to provide carborane cage ligands in the synthesis of other new metallacarborane species or as reagents for the preparation of new materials.

Acknowledgement Support of the U.S. National Science Foundation (grant CHE-8401433) in all the above-mentioned work is gratefully acknowledged.

\section{REFERENCES}

1. Rees, W. S., Jr.; Schubert, D. M.; Knobler, C. B.; Hawthorne, M. F. J. Am. Chem. Soc. 1986, 17, 5369.

2. a) Young, D. A. T.; Willey, G. R.; Hawthorne, M. F.; Reis, A. H., Jr.; Churchill, M. R. Inorg. Chem. 1970, 92, 6663. b) Young, D. A. T.; Wiersema, R. J.; Hawthorne, M. F. J. Amer. Chem. Soc. 1971, 93, 5687. c) Churchill, M. R.; Reis, A. H., Jr.; Young, D. A. T.; Willey, G. R.; Hawthorne, M. F. J. Chem. Soc., Chem. Commun. 1971, 298. 
3. Schubert, D. M.; Rees, W. S., Jr.; Lu, P.-P., Nam, W. W.; Knobler, C. B.; Hawthorne, M. F., submitted for publication.

4. Rees, W. S., Jr.; Schubert, D. M.; Knobler, C. B.; Hawthorne, M. F. J. Am. Chem. Soc. $1986,17,5367$.

5. Schubert, D. M.; Rees, W. S., Jr.; Knobler, C. B.; Hawthorne, M. F. Organometallics 1987, $6,201$.

6. Schubert, D. M.; Rees, W. S., Jr.; Knobler, C. B.; Hawthorne, M. F. Organometallics 1987, 6, 203.

7. Schubert, D. M.; Knobler, C. B.; Hawthorne, M. F., in press.

8. Spencer, J. L.; Green, M.; Stone, F. G. A. J. Chem. Soc., Chem. Commun. 1972, 1178.

9. Hosmane, N. S.; Sirmokadam, N. N. Organometallics 1984, 3, 1119.

10. Jutzi, P.; Galow, P J. Organometal. Chem. 1987, 319, 139.

11. Michailov, B. M.; Potapova, T. V. Izv. Akad. Nauk. SSSR, Ser. Khim., 1968, 5, 1153

12. Cotton, F. A.; Wilkinson, G. Advanced Inorganic Chemistry, 4th ed.; Wiley: New York, $1980 ; \mathrm{p} 1160$.

13. a) Hawthorne, M. F.; Young, D. C.; Wegner, P. A. J. Am. Chem. Soc. 1965, 87, 1818. b) Hawthorne, M. F.; Young, D. C.; Andrew, T. D.; Howe, D. V.; Pilling, R. L.; Pitts, A. D.; Reintjes, M.; Warren, L. F., Jr.; Wegner, P. A. J. Am. Chem. Soc. 1968, 90, 879.

14. a) Atwood, J. L.; Hunter, W. E.; Cowley, A. H.; Jones, R. A.; Stewart, C. A. J. Chem. Soc. 1981, 925, and references therein. b) Heeg, M. J.; Janiak, C.; Zuckerman, J. J. J. Am. Chem. Soc. 1984, 106, 4259.

15. a) Plesek, J.; Hermanek, S. Chem. \& Ind. (London) 1971, 1267. b) Plesek, J.; Hermanek, S. Collect. Czech. Chem. Commun. 1973, 38, 338. c) Plesek, J.; Hermanek, S. Collect. Czech. Chem. Commun. 1974, 39, 821

16. a) Loffredo, R. E.; Norman, A. D.; J. Am. Chem. Soc. 1971, 93, 5587. b) Loffredo, R. E.; Norman, A. D. Inorg. Nucl. Chem. Lett. 1977, 13, 599.

17. a) Stibr, B.; Janousek, Z.; Base, K.; Hermanek, S.; Plesek, J.; Zakharova, I. Collect. Czech. Chem. Commun. 1984, 49, 1891. b) Kukina, G. A.; Porai-Koshits, M. A.; Sergienko, V. C.; Strouf, O.; Base, K.; Zakarhova, I. A.; Stibr, B. Izv. Akad. Nauk. SSSR, Ser. Khim. $1980,1686$.

18. Dustin, D. F.; Evans, W. J.; Jones, C. J.; Wiersema, R. J.; Gong, H.; Chan, S.; Hawthorne, M. F. J. Am. Chem. Soc. 1974, 96, 3085.

19. Hoffman, R.; Lipscomb, W. N. Inorg. Chem. 1963, 2, 231.

20. a) George, T. A.; Hawthorne, M. F. J. Am. Chem. Soc. 1967, 89, 7114. b) George, T. A.; Hawthorne, M. F. J. Am. Chem. Soc. 1968, 90, 1661. c) George; T. A.; Hawthorne, M. F. J. Am. Chem. Soc. 1969, 91, 5475. d) Jones, C. J.; Francis, J. N.; Hawthorne, M. F. J. Am. Chem. Soc. 1972, 94, 8391. e) Jung, C. W.; Baker, R. T.; Hawthorne, M. F. J. Am. Chem. Soc. 1980, 102, 5782. f) Jung, C. W.; Baker, R. T.; Hawthorne, M. F. J. Am. Chem. Soc. $1981,103,810$.

21. a) Tebbe, F. N..; Garrett, P. M.; Hawthorne, M. F. J. Am. Chem. Soc. 1966, 88, 607. b) Garrett, P. M.; George, T. A.; Hawthorne, M. F. Inorg. Chem. 1969, 8, 2008.

22. Hawthorne, M. F.; Pitts, A. D. J. Am. Chem. Soc. 1967, 89, 7115. b) George, A. D.; Hawthorne, M. F. Inorg. Chem. 1968, 8, 1801. c) Hollander, F. J.; Templeton, D. H.; Zalkin, A. Inorg. Chem. 1973, 12, 2262.

23. Schubert, D. M.; Rees, W. S., Jr.; Knobler, C. B.; Hawthorne, M. F., manuscript in preparation.

24. a) Hosmane, N. S.; de Meester, P.; Siriwardane, U.; Islam, M. S.; Chu, S. S. C. J. Chem. Soc., Chem. Commun. 1986, 1421. b) Hosmane, N. S.; de Meester, P.; Siriwardane, U.; Islam, M. S.; Chu, S. S. C. J. Am. Chem. Soc., in press. 